\title{
Incidental tracheal bronchus in a case of Hamman- Rich syndrome
}

\author{
Luca Conti, Christopher Zammit
}

Respiratory Department, Mater Dei Hospital, Msida, Malta

Correspondence to Dr Luca Conti, lucaconti91@gmail.com

Accepted 25 April 2019

\section{DESCRIPTION}

An elderly woman, life-long non-smoker, presented to the emergency department with a dry cough and progressive dyspnoea for the past week. She had no relevant medical history. Physical examination revealed an elevated respiratory rate of 20 breaths per minute and low oxygen saturations of $91 \%$ at room air. There were bilateral basal crepitations on chest auscultation. A chest X-ray showed bilateral multifocal peripheral consolidations.
Urgent blood testing revealed a neutrophilia of $9.42 \times 10^{9} / \mathrm{L}$ (range: $1.90-7.70 \times 10^{9} / \mathrm{L}$ ) with eosinophils of $0.08 \times 10^{9} / \mathrm{L}$ (range: $0.00-0.60 \times 10^{9} / \mathrm{L}$ ). Her $\mathrm{C}$ reactive protein was $7.8(0-5 \mathrm{mg} / \mathrm{L})$. Blood cultures were negative for bacteraemia, and a respiratory screen did not reveal any pathogens. N-terminal pro-b-type natriuretic peptide was $267(5-125 \mathrm{pg} / \mathrm{mL})$. A rheumatoid screen was negative with a normal rheumatoid factor, antinuclear antibody (ANA) and antineutrophil cytoplasmic antibody (ANCA) levels.

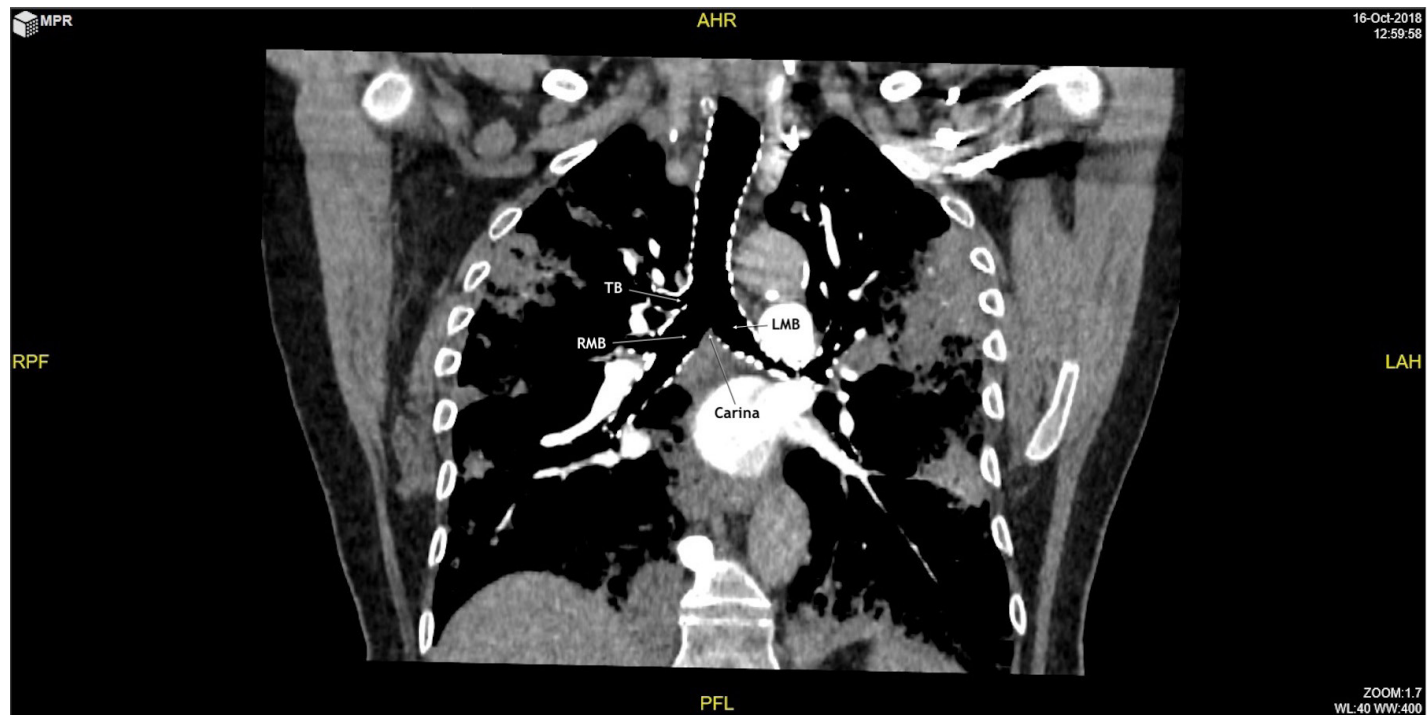

Figure 1 Incidentally, the chest $\mathrm{CT}$, revealed a displaced tracheal bronchus (TB) on multiplanar reconstruction, along with the right main bronchus (RMB) and left main bronchus (LMB), along with the tracheal carina. Multiple air space opacifications with peripheral distribution are visible. Interlobular septal thickening with ground glass changes are also described in both lower pulmonary lobes. Patient orientation vectors - AHR: Anterior, Head, Right; LAH: Left, Anterior, Head; RPF: Right, Posterior, Foot; PFL: Posterior, Foot, Left.

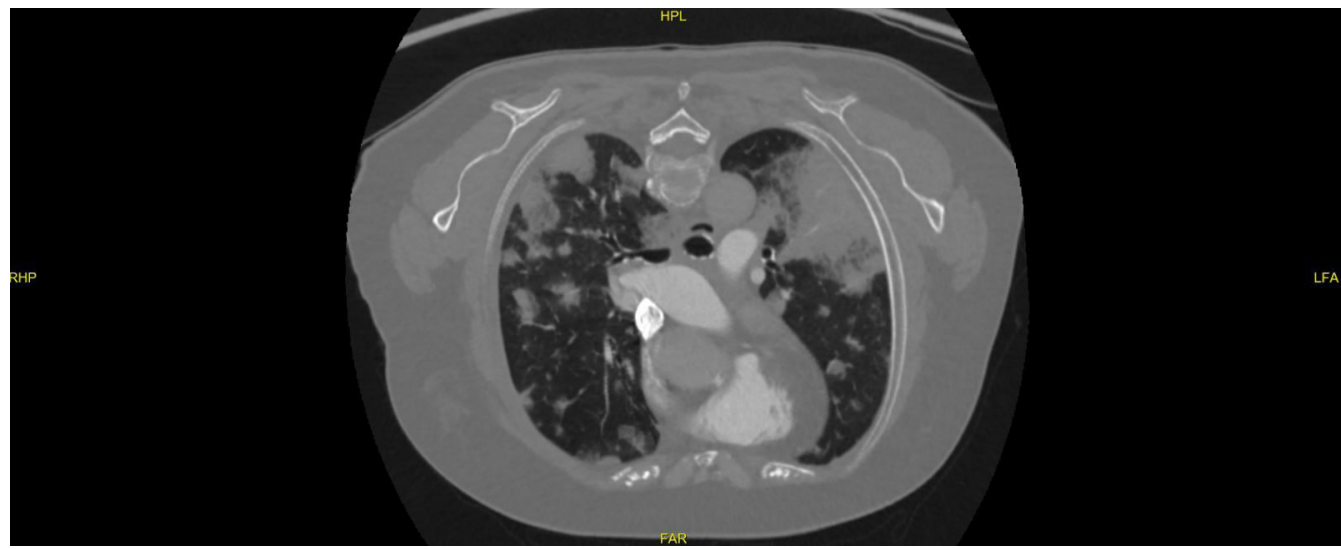

Figure 2 Image showing the bifurcating right upper lobe bronchus. Patient orientation vectors - HPL: Head, Posterior, Left; LFA: Left, Foot, Anterior; FAR: Foot, Anterior, Right; RHP: Right, Head, Posterior. 


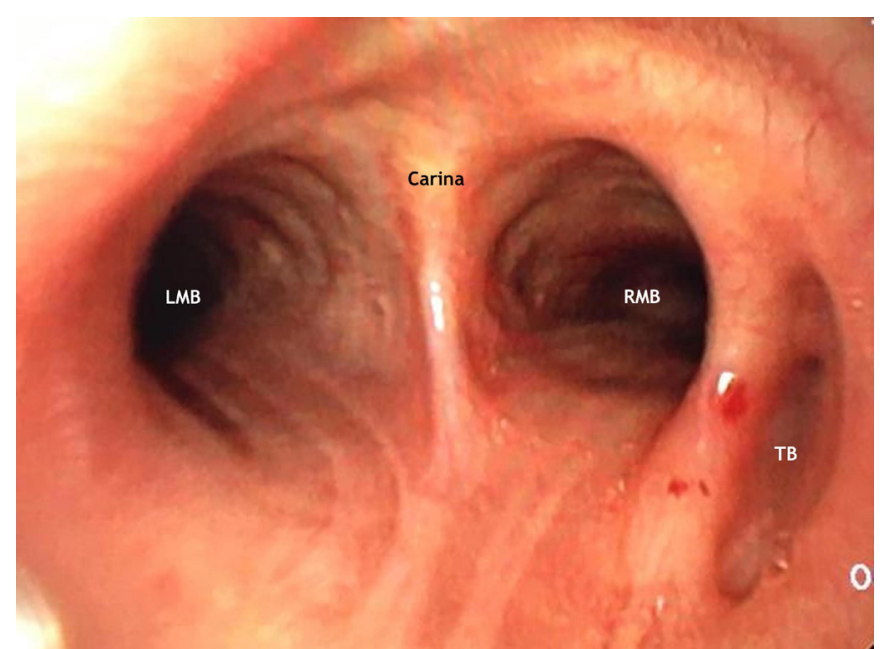

Figure 3 Bronchoscopy view of the displaced type tracheal bronchus. LMB, left main bronchus; RMB, right main bronchus; TB, tracheal bronchus (TB).

A chest CT demonstrated diffuse bilateral, peripheral consolidations with surrounding ground glass and interlobular septal thickening suggestive of a crazy paving pattern. Multiple nodules were present bilaterally, two of which showed mild cavitation. Incidentally, on multiplanar reconstruction, a displaced right upper lobe bronchus was noted on coronal section (figure 1) in addition to the bifurcating right upper lobe bronchus (figure 2).

A flexible bronchoscopy revealed a displaced lobar tracheal bronchus arising from the right tracheal wall, approximately one tracheal ring above the carina (figure 3). There were no other macroscopic findings except for significantly increased mucus within the bronchi. A bronchoalveolar lavage (BAL) was performed with the following normal differential cell profile: macrophages: $73 \%$, neutrophils: $24 \%$, lymphocytes: $3 \%$ and eosinophils: $0 \%$. Unfortunately, the patient was not fit to undergo an open or thoracoscopic lung biopsy to obtain a histological diagnosis.

Despite a prolonged course of antibiotics, and concurrent use of high dose systemic glucocorticoids, the patient showed no clinical improvement and eventually passed away in hospital. A diagnosis of Hamman-Rich syndrome (acute interstitial pneumonia (AIP)) was reached by exclusion.
AIP is a rare and fulminant form of diffuse pulmonary fibrosis that is associated with a high inpatient mortality and generally occurs in previously healthy individuals. The diagnosis of AIP is based on the presence of clinical findings of idiopathic acute respiratory distress syndrome and pathological confirmation of diffuse alveolar damage.

This patient also had an uncommon feature, a tracheal bronchus, which is a congenital anatomical variant of an aberrant bronchus supplying the right upper lobe that arises directly from the supracarinal trachea. Its incidence ranges from $0.1 \%$ to 1.9\%. Tracheal bronchi are classified into displaced and supernumerary types. In the former, the right upper lobe bronchus bifurcates into two, and the accessory bronchus supplies the apical segment of the right upper lobe. In the supernumerary type, a normal trifurcating segmental bronchus is present in addition to the accessory bronchus. Most patients remain asymptomatic but occasionally patients may present with persistent or recurrent pneumonia, atelectasis and bronchiectasis involving the right upper lobe.

\section{Learning points}

It is important to recognise a tracheal bronchus preoperatively, as a properly placed endotracheal tube cuff may cause obstruction, thus resulting in intraoperative hypoxaemia, atelectasis or both.

- In addition to the conventional axial CT scan images, multiplanar reconstruction images and virtual bronchoscopy images aid to depict the exact anatomy of the airways.

- In the absence of clinical, serological or BAL evidence of an alternative diagnosis and clinical findings of idiopathic acute respiratory distress syndrome, a presumptive diagnosis of acute interstitial pneumonia may be reached, especially in patients who are not fit enough to undergo a lung biopsy.

Contributors LC: collating clinical information, performing diagnostic testing, literature review, writing and revising the manuscript. CZ: performing diagnostic testing, writing and revising the manuscript.

Funding The authors have not declared a specific grant for this research from any funding agency in the public, commercial or not-for-profit sectors.

Competing interests None declared.

Patient consent for publication Not required.

Provenance and peer review Not commissioned; externally peer reviewed.

Copyright 2019 BMJ Publishing Group. All rights reserved. For permission to reuse any of this content visit https://www.bmi.com/company/products-services/rights-and-licensing/permissions/

BMJ Case Report Fellows may re-use this article for personal use and teaching without any further permission.

Become a Fellow of BMJ Case Reports today and you can:

- Submit as many cases as you like

- Enjoy fast sympathetic peer review and rapid publication of accepted articles

- Access all the published articles

- Re-use any of the published material for personal use and teaching without further permission

For information on Institutional Fellowships contact consortiasales@bmjgroup.com

Visit casereports.bmj.com for more articles like this and to become a Fellow 